\title{
Insulation Problem Identified
}

National Cancer Institute

\section{Source}

National Cancer Institute. Insulation Problem Identified. NCI Thesaurus. Code C92068.

Problems due to inadequate or incorrect electrical insulation material. 